\title{
Analysis for the one-stop logistics management of fresh agricultural products
}

\author{
Yan-Jun Wang ${ }^{\mathrm{a}}$, Hong-Mei Gao ${ }^{a^{*}}$, Yu-Chuan Liu ${ }^{b}$ \\ ${ }^{a}$ Department of Economic Management, Tianjin Agricultural University, Tianjin, China \\ ${ }^{\mathrm{b}}$ Department of Information Management, Tainan University of Technology, Tainan, Taiwan \\ *Corresponding author: Hong-Mei Gao, Ph.D., gaohongmei@126.com
}

\begin{abstract}
Issues and concerns for food safety, agro-processing, and the environmental and ecological impact of food production have been attracted many research interests. Application of one-stop logistics service focused on the supply chain process integration for fresh agricultural products is studied. A collaborative research project for the supply and logistics of fresh agricultural products in Tianjin was performed. Requirement analysis for the one-stop logistics management information system is studied. Development of this research is crucial for the solution of one-stop logistics management information system for fresh agricultural products.
\end{abstract}

Key words: one-stop logistics service; fresh agricultural products; model-driven business transformation

\section{Introduction}

The heightened awareness of food-related safety issues among food consumers drives the demand for more information about the vertical food supply chain about the origin and handling of the basic commodities and food products generated and consumed throughout the world. The major information technology (IT) development lines, the support potential of their integration, organizational requirements for the utilization, and possible consequences for the future organization of the agro-food sector were reviewed (G. Schiefer ${ }^{1}$ ). Traceability is an essential subsystem of quality management, and must be managed by setting up a traceability system, which keeps the data tracking of product routes and of selected attributes. Food traceability requires that all stakeholders within the food supply chain, including agriculture and food producers, food manufacturers, retailers, etc., must be able to identify the source of all raw materials and ingredients to whom the products have been sold. The traceability system is to provide services for the supply chain actors on cooperative basis of the mutual interests (M. Varga and B. Csukas ${ }^{2}$ ). Opara ${ }^{3}$ reviewed the concepts of supply chain management and traceability in agriculture and highlighted the technological challenges, including food product label and identification, activity/process characterization, information systems for data capture, analysis, storage and communication, and the integration of the overall traceable supply chain in implementing traceable agricultural supply chains.

A new model and prototype of a new Farm Information Management System was developed (C. G. Sørensena et al. ${ }^{4}$ ). Kelepouris et al. ${ }^{5}$ suggested a radio frequency identification (RFID) technology and outlined both information data model and system architecture that made traceability feasible and easily deployable across a supply chain. Based on an integration of alphanumerical codes and RFID technology, the traceability system for Parmigiano Reggiano (the famous Italian cheese) was developed (A. Regattieri et al. ${ }^{6}$ ). Manthou et al. ${ }^{7}$ provided 
empirical insights regarding the use of Internet-based applications in the agro-food supply chain by focusing on the Greek fruit canning sector. The logistics and information flow play an important role in the fresh agricultural products supply chain. The purpose of this research is to further provide a complete study on the issues and solutions for the one-stop logistics service management of fresh agricultural products. A full life-cycle business-to-technology method, model-driven business transformation MDBT (S. Kumaran ${ }^{8}$ and S. Kumaran et al. ${ }^{9}$ ), is both a business transformation methodology and a set of innovative technologies that allow business strategies to be realized by choreographing workflow tools. The MDBT approach is applied to propose an integrated solution. Development of this research is crucial for the solution of one-stop logistics management in fresh agricultural products.

\section{Model-driven business transformation approach}

Model-driven business transformation, MDBT developed by IBM research, uses formal models to explicitly define the structure and behavior of a business component. In the MDBT approach, the transformation process begins with the identification of the strategic goals and objectives of the business component. A business operation model is different from the more familiar workflow models. A business operation model, on the other hand, defines the key business activities and the operations performed on these activities. The third step of MDBT is the judicious use of technology to support the execution of business operations. This involves the generation of a platform-independent solution composition model and the realization of this model on a specific software platform. The final step in MDBT is to create an implementation of the IT solution on a specific IT platform. Once the solution is deployed, business owners can monitor business performance using KPIs and continuously improve the models, both at the business and IT levels, based on this performance analysis.

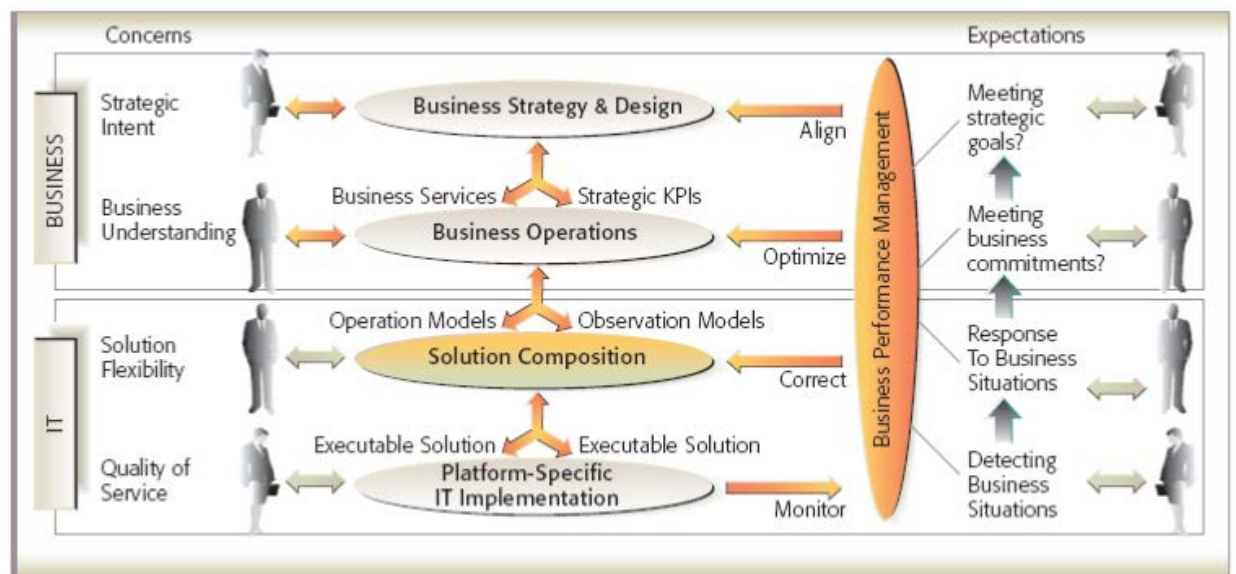

Fig. 1 - Model-driven business transformation framework, from S. Kumaran et al. ${ }^{9}$.

The infrastructure of fresh agricultural products logistics supply chain management services can be summarized as shown in Fig. 2. The logistics information during the transportation and storage for all the supply chain stages to ensure the completeness of the traceability management. By applying MDBT approach, the definition of goals and objectives should be firstly analyzed in strategy layer. As the project team reviewed the current fresh agricultural products supply chain in Tianjin, the first two issues are the product loss during the logistics procedure and cost (and/or effectiveness) of the cold chain logistics. The objectives are consequently to improve the effectiveness and efficiency for fresh agricultural products 
logistics management. One-stop supply chain management service is an integrated model of the logistics services to reduce logistics cost and promote logistics efficiency of fresh agricultural products.

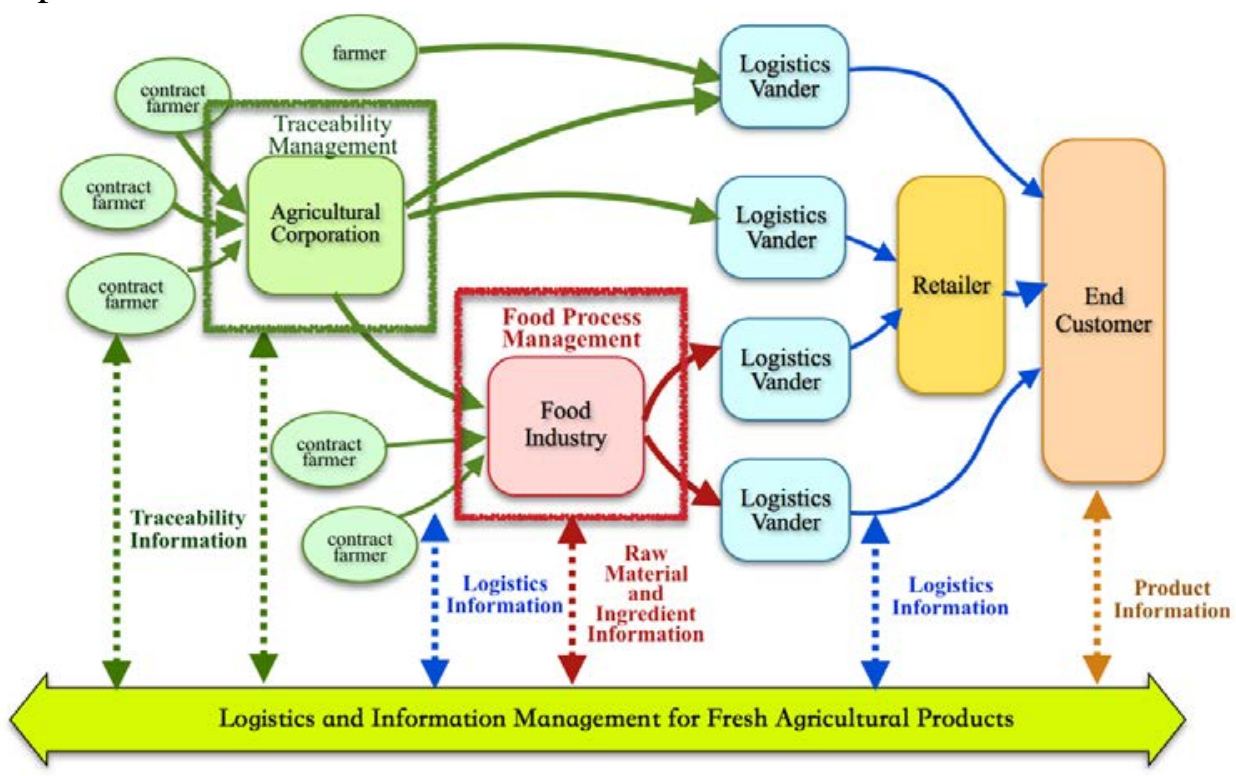

Fig. 2 - Infrastructure of the one-stop logistics management for fresh agricultural products.

\section{One-stop logistics service analysis by MDBT}

Detail solution requirements are further studied through the supply chain processes. Figure 2 shows that the logistics information flow between the supply chain enterprises can be shared and integrated for further enhancement of the supply chain management efficiency. The information system must be designed to cope with the intricate farming data, food processing information, and the rigmarole product transportation and storage information. The platform independent solution requirements for one-stop logistics service of fresh agricultural products are proposed in this paper. The system platform should cover information requirements of the farming, food processing, and logistics management of the supply chain processes. Schematic diagram of the one-stop logistics service management for fresh agricultural products supply chain is suggested as shown in Fig. 3. The specific functional requirements from configuration management analysis are summarized in the following sections.

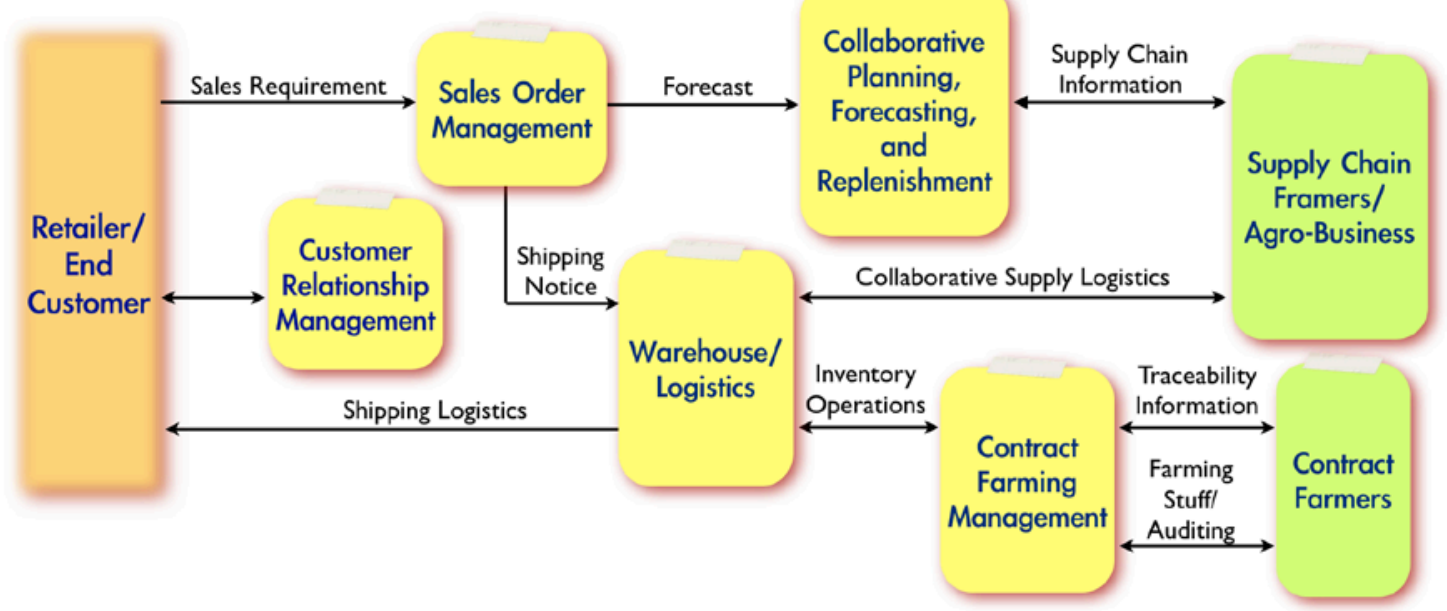

Fig. 3 - System integration architecture for the one-stop information management platform for traceability and logistics management of the fresh agricultural products supply chain. 


\subsection{Functional analysis for the one-stop logistics service}

The one-stop logistics service system not only coordinate the links between the various nodes, but also help to make accurate estimation on the customers' needs through effective information analysis. The cold chain logistics companies should provide procurement, distribution, logistics and other value-added services to meet customers' demand. The requirement of the one-stop logistics service can be summarized as:

- One-stop procurement service can achieve the purpose of door-to-door procurement. It is much more complex for fresh agricultural products because of the storage conditions and variety in the combinations and substitute of product types. One-stop procurement service provides the opportunity for industries to obtain all procurement from their supplier to utilize the operation effectiveness.

- Constructing a one-stop distribution channel is to integrate different supply chain services platforms based on the satisfaction of customer needs. A win-win situation can be reached that the brand owners can reach more customers, and the customers can have more choices of product resources.

- The logistics management under the One-stop supply chain service platform cannot become possible without the collection, analysis, processing and timely update of the supply chain data. Information of the products, financial, and logistics can be collected through proper information system design. One should note that the main challenge is the information integration of the all venders in the supply chain.

- Food traceability can usually be found by attaching a 2-dimensional label, QR (quick response) code is the usual case, on the package of the food or agro-products. A mobile farming information system to collect the farming data and directly transmitted to the traceability system by cell phone and two dimensional codes was proposed in (Y. C. Liu and H. M. Gao ${ }^{10}$ ). All the required farming operations are encoded into QR codes and every farming operation is transformed into distinct QR code label. By scanning the proper QR code, farmers can easily upload the operation messages into the traceability data system. The mobile traceability data collection system can be applied to the other supply chain venders.

\subsection{Supporting system for the one-stop logistics service}

The support systems of one-stop supply chain logistics service platform for fresh agricultural products include cold chain logistics enterprise, information technology, logistics network, corporate reputation and professional team. The logistics service network provides an important foundation, such as the layout of distribution network, cold storage facilities, and information network, for one-stop supply chain services. Considering the complexity of the fresh agricultural products supply chain, high-quality and professional staff team is vital for the one-stop supply chain services. The operation team that is adaptive to the changing market and customer requirements is crucial to develop the logistics service platform. Effective project management is indispensable for the system design and implementation of the project consists of design, analysis, simulation, and verification of information systems. Industries must keep abreast on controlling logistics risk and improving the effectiveness and efficiency of logistics enterprises and customer service. The replenishment (CPFR) is the major solution to overcome the highly uncertain property of the supply and demand for fresh agricultural 
products. The key requirements for the system shown in Fig. 3 can be summarized as followed.

- CPFR for the fresh agricultural products supply chain with the considerations of the farming production and the market requirements for proper farming control and products dispatching is necessary to minimize the unbalance of the supply-and-demand of fresh agricultural products.

- Detail analysis for the traceability information of contract and supply farmers is necessary to assure the software systems can achieve properly the control and traceability purpose.

- The warehouse management of fresh agricultural products is quite different from the general grocery items. The storage condition, labelling, and packing need to be carefully reviewed.

- The integrated platform consists of different venders of the supply chain, the effective interface definition and communication protocol design are crucial for the success of the information systems.

\subsection{Strengthen the one-stop logistics information service}

Considering the specific characteristics of the fresh agricultural products, effective professional staff team, that is adaptive to the market changing, customer requirements, and the operational process to the last mile of customer, is vital to support the one-stop supply chain service. An efficient team assessment management to ensure the successful implementation of one-stop service system is necessary. Venders in the fresh agricultural products supply chain are usually located far away from food industries, retailer, and customers. Transportation of fresh agricultural products can be summarized in two manners. The first type is transported directly by the food industries (or agricultural corporations). The other is to be delivered by the third-party services such as DHL. The quality of transportation and fresh agricultural products must be controlled and guaranteed during transportation. The cold chain logistics is hence become inevitable. As to provide and integrate the logistics information, the cold chain logistics vehicle need to be upgraded with information accession and transmission. Some suggestions to strengthen the one-stop service information platform are listed:

- It is a great challenge to share information and reduce fluctuations among the different corporations in the fresh agriculture product supply chain. The fresh cold chain related enterprises should re-coordinate to achieve risk-sharing and benefit-sharing. Detailed contract should be compromised to encourage the supply chain members to work with the occurrence of unexpected events to increase mutual trust.

- Solution enhancement of the one-stop logistics service can be divided into two aspects: the hardware and software solutions. Hardware solutions should be designed to cope with that integrate various types of equipment involved in material flow including transportation, handling, and storage.

- Software solution is to provide an efficient one-stop logistics management platform system for the integration of complex logistics information including the products receiving and recording, warehouse entrance and record, transportation management, and storage management of automatic storage location assignment, load to storage location, unload from storage location, lot split, storage location change, and inventory check. 


\section{Conclusions}

The fresh agricultural products supply chain is reviewed and the one-stop logistics management requirements are studied based on the project experience in Tianjin. Because of the food safety concern and the complex business characteristics through the food supply chain, the MDBT approach to provide a service-oriented-architecture solution is proposed in this paper. Three major considerations for the one-stop logistics management platform, including the functional analysis, supporting system, and strengthen for the one-stop logistics service, are suggested. With the proposed functional requirements, the results of this paper can be fruitful for the further design of the fresh agricultural products logistics information management systems.

\section{Acknowledgements}

This work was financially supported by the National Training Program of Innovation and Entrepreneurship for Undergraduates 2016 of the Ministry of Education of PRC (project no. 201610061083) and Tianjin Administration of Foreign Affairs (project no. 20171200248).

\section{References}

1. G. Schiefer, New technologies and their impact on the agri-food sector: an economists view, Comput. and Electron. in Agr. 4(2) (2004) 163-172.

2. M. Varga and B. Csukas, On the way toward the sector spanning agrifood process traceability, Agricultural Informatics 1(1) (2010) 8-18.

3. L. U. Opara, Traceability in agriculture and food supply chain: a review of basic concepts, technological implications, and future prospects, J. of Food Agric. Environ. vol. 1(1) (2003) 101-106.

4. C. G. Sørensena, S. Fountasb, E. Nashf, L. Pesonend, D. Bochtisa, S. M. Pedersene, B. Bassoc, S. B. Blackmoreg, Conceptual model of a future farm management information system, Comput. and Electron. in Agr. 72(1) (2010) 37-47.

5. T. Kelepouris, K. Pramatari, and G. Doukidis, RFID-enabled traceability in the food supply chain, Ind. Mana. Data Syst., 107(2) (2007) 183-200.

6. A. Regattieri, M. Gamberi, and R. Manzini, Traceability of food products: General framework and experimental evidence, J. of Food Eng. 81(2) (2007) 347-356.

7. V. Manthou, A. Matopoulos, and M., Vlachopoulou, Internet-based applications in the agri-food supply chain: a survey on the Greek canning sector, J. of Food Eng., 70(3) (2005) 447-454.

8. S. Kumaran, Model Driven Enterprise, Proceedings of the Global Enterprise Application Integration Summit, Banf, Canada, 2004, 166-180.

9. S. Kumaran, P. Bishop, T. Chao, P. Dhoolia, P. Jain, R. Jaluka, H. Ludwig, A. Moyer, and A. Nigam, Using a Model-Driven Transformational Approach and ServiceOriented Architecture for Service Delivery Management, IBM System Journal, 46(3) (2007) 513-529.

10. Y. C. Liu and H. M. Gao, Development and Applications of Mobile Farming Information System for Food Traceability in Health Management, in Applied Computing in Medicine and Health, edited by D. Al-Jumeily, A. Hussain, C. Mallucci, and C. Oliver, Elsevier, Aug. 2015, 244-268. 